\title{
Collapse of an iconic conifer: long-term changes in the demography of Widdringtonia cedarbergensis using repeat photography
}

\author{
J. D. M. White ${ }^{1,2}$, S. L. Jack ${ }^{1,2}$, M. T. Hoffman ${ }^{1,2^{*}}$, J. Puttick ${ }^{1,2}$, D. Bonora ${ }^{1,2}$, V. Visser ${ }^{3,4}$ and E. C. February ${ }^{2}$
}

\begin{abstract}
Background: Conifer populations appear disproportionately threatened by global change. Most examples are, however, drawn from the northern hemisphere and long-term rates of population decline are not well documented as historical data are often lacking. We use a large and long-term (1931-2013) repeat photography dataset together with environmental data and fire records to account for the decline of the critically endangered Widdringtonia cedarbergensis. Eighty-seven historical and repeat photo-pairs were analysed to establish 20th century changes in $W$. cedarbergensis demography. A generalized linear mixed-effects model was fitted to determine the relative importance of environmental factors and fire-return interval on mortality for the species.

Results: From an initial total of 1313 live trees in historical photographs, 74\% had died and only 44 (3.4\%) had recruited in the repeat photographs, leaving 387 live individuals. Juveniles (mature adults) had decreased (increased) from $27 \%$ (73\%) to $8 \%$ (92\%) over the intervening period. Our model demonstrates that mortality is related to greater fire frequency, higher temperatures, lower elevations, less rocky habitats and aspect (i.e. east-facing slopes had the least mortality).

Conclusions: Our results show that $W$. cedarbergensis populations have declined significantly over the recorded period, with a pronounced decline in the last 30 years. Individuals that established in open habitats at lower, hotter elevations and experienced a greater fire frequency appear to be more vulnerable to mortality than individuals growing within protected, rocky environments at higher, cooler locations with less frequent fires. Climate models predict increasing temperatures for our study area (and likely increases in wildfires). If these predictions are realised, further declines in the species can be expected. Urgent management interventions, including seedling out-planting in fireprotected high elevation sites, reducing fire frequency in higher elevation populations, and assisted migration, should be considered.
\end{abstract}

Keywords: Temperature, Conifer, Repeat photography, Population change, Climate change, Fire, Cederberg

\section{Background}

In a recent global review of forest tree species, climateinduced physiological stress driven by drought and high temperatures was found to be a major cause of mortality in the last 40 years [1]. Affected trees were also more vulnerable to climate-mediated processes such as insect or pathogen attack and wildfires. Conifers represented more

\footnotetext{
*Correspondence: timm.hoffman@uct.ac.za

${ }^{2}$ Department of Biological Sciences, University of Cape Town, Cape Town, South Africa

Full list of author information is available at the end of the article
}

than $40 \%$ of the 88 reviewed cases of mortality [1] and have recently been found to be particularly vulnerable to a warming climate [2].

The particularly rapid decline of the charismatic southern African endemic, Widdringtonia cedarbergensis Marsh [3] over the last century is representative of this global decline in conifers and has led the species to be listed as critically endangered under the current IUCN Red List of Plants [4]. While the diminishing number of W. cedarbergensis individuals have been anecdotally noted since the early $1800 \mathrm{~s}$ [5] and the focus of more 
systematic observation over the last 50 years (see [3]), there is as yet no quantitative evidence documenting the rate of decline and no plausible hypothesis for a cause.

The prevailing causal theories for the decline in $W$. cedarbergensis are (a) 18th and 19th century over-exploitation of the tree as a timber source which reduced and fragmented populations, thereby increasing 'edge-effects' and the likelihood of succumbing to fire [6-8], (b) late Quaternary climate change with warmer temperatures and less winter precipitation leading to a shift in the composition of co-occurring species with consequent changes in the fire regime $[9,10]$, (c) recent anthropogenic climate change, leading to temperature increases and aridity in the north-western areas of the fynbos biome, thereby increasing $W$. cedarbergensis mortality [11], and (d) the negative influence of insects and pathogens on reproductive output and survival [12].

The vegetation for the Cederberg Wilderness Area (CWA) is termed fynbos, a fire-prone vegetation type that includes many fire-adapted species with a fire return interval of approximately 11-15 years [13]. Fire is an important disturbance mechanism in fynbos and is thought to have had a strong influence in shaping the ecology and evolution of fynbos species [14]. W. cedarbergensis, however, is conspicuous in this environment in that it shows little or no adaptation to cope with fire. Mature trees are often killed by fire and display no resprouting ability, there is no canopy-stored seedbank, sapling growth rates are relatively slow, and the trees take much longer to reach reproductive maturity (ca. 40 years) than any co-occurring shrubs or trees [15]. Given such sensitivity to fire, an unfavourable fire regime can be very detrimental to this species. More recently there has been an increase in fire frequency with as many as six fires occurring in some parts of the Cederberg between 1977 and 2003 [16]. This suggests that the current fire return interval could be too short to allow for adequate establishment and reproductive output to maintain viable populations of the species $[9,13]$.

Widdringtonia cedarbergensis individuals are usually associated with rocky cliffs, outcrops and east facing slopes at high elevations and are rarely found at lower elevations, on flatter ground and deeper soils $[3,17]$. This association with higher-lying rocky sites has not only been attributed to temperature amelioration [7] and protection from fire [3], but has also been suggested to give trees reliable access to available water trapped between bedding planes [11]. This water supply is reliant on regular rainfall, and therefore any change in the amount or seasonality of rainfall that may lead to a decline in plant available water will adversely affect the trees. Given that the CWA is projected to be one of the first areas in the Western Cape Province in South Africa to be affected by warming and drying due to anthropogenic climate change [18], the likely sensitivity of W. cedarbergensis to elevated temperatures and reduced moisture levels is concerning.

This study draws on a large collection of historical photographs of W. cedarbergensis (ca. 1931-1951 and 1960-1987) which were relocated and retaken (20072013), and represent the longest visual record of change in W. cedarbergensis populations to date. Here we (a) describe the pattern of recruitment and mortality of the species for the last 80 years, (b) evaluate the relationship between the degree of observed mortality and several likely environmental contributors to this mortality, and (c) speculate on the extent to which short-versus longterm changes in rainfall, temperature and fire regimes have affected the current distribution and demography. We use our findings to make recommendations regarding the future conservation of the species.

\section{Methods}

Study area and photograph sites

Widdringtonia cedarbergensis, commonly known as the Clanwilliam cedar, is endemic to the Cederberg Mountains of the Western Cape Province in South Africa. It has a patchy distribution between 900 and 1500 metres above sea level over approximately $250 \mathrm{~km}^{2}$, and typically grows in quartz-derived sandstone soils [19]. The Cederberg experiences a Mediterranean-type climate with the majority of frontally-derived rainfall received during the cooler winter months (April-September), while summers are hot and dry. Cederberg vegetation is comprised mainly of Cederberg Sandstone Fynbos, which is a sclerophyllous and fire-prone vegetation type [20, 21].

At the elevations at which it grows, W. cedarbergensis is often the only tree species in the landscape. It is also uniquely different in growth form from the only other tree, Protea nitida and therefore easily distinguished. A historical collection of 87 photographs unambiguously showing W. cedarbergensis trees, taken between 1931 and 1987 by several photographers, were used in the analysis. Historical photographs were located in the Skerpioenspoort, Middelberg, Welbedacht and Heuningvlei regions and were repeated during three separate visits to the Cederberg in 2007, 2012 and 2013 (Fig. 1; see Additional file 1: Table S1 for further information on repeat photographs). In order to retake the historical photograph, sites were first located using a combination of topographical maps, notes accompanying photographs and landscape features. The exact position of the original camera was then determined in the field and, with the aid of a tripod for stability, the repeat photograph was taken using a high specification digital camera (Canon 5D MkII, Canon Inc., USA). Detailed site information, such as GPS co-ordinates, elevation, aspect, degree of 




Fig. 1 Map of localities of sampled Widdringtonia cedarbergensis individuals. The locations of $W$. cedarbergensis individuals in four different regions in the Cederberg Wilderness Area, Western Cape, South Africa: $a$ Heuningvlei, $b$ Skerpioenspoort, c Middelberg and $d$ Welbedacht. Features of interest include the weather stations at Algeria Forest Station and Clanwilliam

rockiness, general ecological description and description of major changes in W. cedarbergensis and other vegetation, were recorded for each site.

\section{Population dynamics over time}

To match the photo-pairs, the repeat photograph was resized so that a distance between two fixed features 
common to both images was identical. The repeat photograph was then overlain on the historical photograph and rotated and shifted so that landscape features aligned exactly. The matched historical and repeat photographs were then saved independently (Adobe Systems Inc., 2010) and individual trees labelled according to whether these were living, dead or had recruited since the historical photograph was taken (Fig. 2). Mortality and recruitment probabilities were then calculated relative to the digitised original historic image. Age class (juvenile, mature adult and senescent/dead) and degree of rockiness were subjectively scored in both historical and repeat photographs. A juvenile tree was estimated to be generally shorter than $2 \mathrm{~m}$ tall with a thin, erect stem and no branching of the primary trunk. A mature adult was usually taller than a juvenile, with a thick primary trunk and a considerable extent of secondary branching, while senescent/dead individuals had only one or two branch tips with foliage or no foliage at all. Depending on the degree of rockiness, photograph sites were classified as either open $(<25 \%$ rockiness), protected $(25 \%<$ rockiness $<75 \%)$ or well protected $(>75 \%$ rockiness and

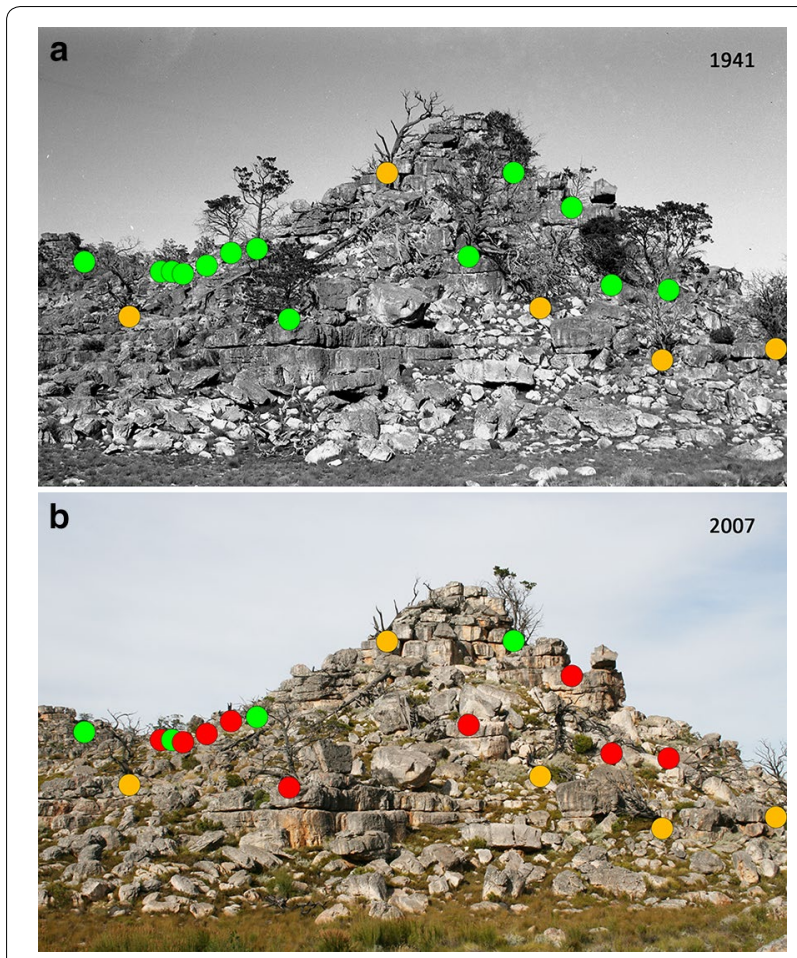

Fig. 2 Example photo-pair. a Historical photograph taken by Ken Howes-Howell in 1941 and $\mathbf{b}$ repeat photograph taken by Timm Hoffman in 2007 at Vogelgesang, Skerpioenspoort. Thirteen living Widdringtonia cedarbergensis (green dots) and five skeletons (orange dots) were recorded in the historical photograph. Only four individuals had survived until 2007, with nine having died (red dots) and no new recruits located within a rocky outcrop). Age class structure was then analysed within three broad time periods, namely 1931-1951 and 1960-1987 (historical photographs), and 2007-2013 (repeat photographs). These time periods, hereafter referred to as 'early', 'middle' and 'recent' respectively, were then compared using Chi squared tests, while the number of trees per photograph was compared for these periods using the nparcomp package in $\mathrm{R}$ (version 3.1.0) [22, 23].

\section{Environmental trends}

The available fire history for the CWA was accessed via the SANBI Biodiversity GIS portal (http://bgis.sanbi.org), and fire frequency computed for each of the 87 photosites and identified regions [24]. Using GPS co-ordinates for each tree, mean annual temperature $\left({ }^{\circ} \mathrm{C}\right)$ and annual precipitation $(\mathrm{mm})$ values for the period 1950-2000 were extracted from the interpolated Worldclim climate surface [25]. The spatial resolution (30 arc sec) of WorldClim data did not allow for quantifications of temperature and precipitation for each tree. This is similarly the case for fire frequency data, where the temporal resolution did not exactly match the date of all historical photographs, while the myriad micro-habitats that may shelter plants from fires could not be mapped within fire 'polygons' However, the model variables represent the best available spatial and temporal estimates for climatic conditions presently available. Google Earth was used to determine latitude, longitude and aspect value for each tree [26]. Primary cardinal directions and intercardinal ranges were grouped for ease of analysis (for example: $315^{\circ}<\mathrm{N} \leq 45^{\circ}$ ). Further information on the source, resolution and unit of measurement of modelled variables can be found in Additional file 2: Table S2. For climate trend analysis, historical climate data was obtained from the South African Weather Service for Clanwilliam $\left(32^{\circ} 10^{\prime} 52.52^{\prime \prime} \mathrm{S}, 18^{\circ} 53^{\prime} 37.64^{\prime \prime} \mathrm{E}\right)$ and the Agricultural Research Council for the Cape Nature Offices at Algeria $\left(32^{\circ} 22^{\prime} 28.65^{\prime \prime} \mathrm{S}, 19^{\circ} 3^{\prime} 38.34^{\prime \prime} \mathrm{E}\right)$ (Fig. 1). Clanwilliam and Algeria were the closest stations with long-term precipitation records (1870-2010 and 1908-2008, respectively). No temperature records exist for Algeria while Clanwilliam has a temperature record from 1963 to 2010. We used the 'segmented' package in $\mathrm{R}$ to determine whether regression models of the precipitation and temperature records had unknown break-points [23, 27].

\section{Regional W. cedarbergensis population dynamics}

All statistical analyses were performed in the R statistical programme [23]. For each region, defined as discrete, geographically separate populations, probability of mortality (Model 1) or recruitment (Model 2) was determined by fitting a generalized linear mixed-effects model 
(GLMM) in the 'MASS' package [28]. Habitat, aspect, mean annual temperature $\left({ }^{\circ} \mathrm{C}\right)$ and fire frequency were fitted as fixed effects, while region and photograph site were fitted as random effects. This analysis included both plantations established at the end of the 19th century, as well as natural stands of trees. These models were simply used to describe regional differences in mortality and recruitment between $W$. cedarbergensis populations and not to infer abiotic correlates of population dynamics.

\section{Correlates of W. cedarbergensis tree mortality}

Only natural stands were used in the analysis to determine environmental and climatic correlates of W. cedarbergensis mortality (Model 3). This model exhibited significant positive spatial autocorrelation for spatial lags up to about $5 \mathrm{~km}$ (measured using spatial correlograms from the 'ncf' package [29]; see Additional file 3: Figure S1). To account for spatial autocorrelation we included a spatial autocovariate using an exponential correlation structure with latitude and longitude coordinates. The GLMM used to determine correlates of mortality included mortality as the binary response variable, habitat, aspect, mean annual temperature $\left({ }^{\circ} \mathrm{C}\right)$ and fire frequency as fixed effects and region and photograph site as random effects with a binomial family link. We used Wald tests to determine overall significance of the fixed effects [30].

\section{Results}

\section{Population dynamics}

A total of 1313 living trees were recorded when plantations and natural populations were combined across all historical photographs. Of these, 967 individuals (74\%) had died and there were 44 new recruits (Heuningvlei: $\mathrm{n}=2$, Welbedacht: $\mathrm{n}=9$, Skerpioenspoort: $\mathrm{n}=3$ and Middelberg: $\mathrm{n}=30$ ), with 3 of these recruits having died in the intervening period, leaving a total of 387 individuals alive. When considering only natural populations at Welbedacht, Skerpioenspoort and Middelberg, 597 individuals (73\%) out of 821 had died, leaving only 264 trees alive.

For natural stands, there was no significant change in the average number of trees recorded in each photograph between early $(8.65 \pm 0.95, \mathrm{n}=51)$ and middle $(6.86 \pm 0.83, \mathrm{n}=28)(\mathrm{p}=0.787)$ periods. However, there was a significant decline $(\mathrm{p}<0.001)$ in trees per photograph for the recent period $(2.71 \pm 0.34, \mathrm{n}=79)$. The early period had a significantly greater proportion of juveniles $(27 \%)$ than the middle $(5 \%)\left(\mathrm{X}^{2}=54.29, \mathrm{df}=1, p\right.$ value $<0.001)$ and recent period $(8 \%)\left(\mathrm{X}^{2}=36.68, \mathrm{df}=1\right.$, $\mathrm{p}$ value $<0.001)$. However, no significant change was found in the proportion of juveniles between the middle and recent periods $\left(\mathrm{X}^{2}=1.27, \mathrm{df}=1, \mathrm{p}\right.$ value $\left.=0.259\right)$.

\section{Regional population dynamics}

The plantation at Heuningvlei had the highest probability of mortality (mean \pm SD: $0.90 \pm 0.04$ ) followed by the natural populations at Skerpioenspoort $(0.70 \pm 0.08)$ and Middelberg $(0.69 \pm 0.13)$ and then Welbedacht $(0.60 \pm 0.06)$ (Fig. 3). Welbedacht had the highest probability of recruitment $(0.13 \pm 0.08)$, followed in order by Middelberg $(0.06 \pm 0.04)$, Skerpioenspoort $(0.04 \pm 0.02)$ and lastly Heuningvlei (0.02 \pm 0.01$)$ (Fig. 3).

\section{Environmental trends}

The range in fire frequency for all photo-sites was between three and eight fires over the recorded period (1944-2012). Middelberg experienced the highest median fire frequency of five fires, while Welbedacht experienced the lowest median of three fires (Fig. 4). Frequency histograms indicated mixed trends in the lengths of fire return intervals over time at the respective populations. Only Middelberg displayed a generally decreasing fire return interval (i.e. more frequent fires) through time (Additional file 4: Figure S2).

Despite high inter-annual variability, precipitation increased significantly from 1908 to 2008 at Algeria ( $<<0.001$ ), but showed no significant trend at Clanwilliam only $25 \mathrm{~km}$ away (Additional file 5 : Figure S3). The ten year mean rainfall amount was also significantly higher $(636 \pm 51 \mathrm{~mm})$ at Algeria relative to Clanwilliam $(177 \pm 17 \mathrm{~mm})(\mathrm{df}=198, \mathrm{~F}=564, \mathrm{p}<0.001)$. There was a significant increase $(\mathrm{p}<0.05)$ in temperature of approximately $0.6{ }^{\circ} \mathrm{C}$ at Clanwilliam over the recording period with segmented regression indicating that most of this increase occurred after 1996 (Fig. 5).

\section{Correlates of $W$. cedarbergensis tree mortality}

Fire frequency, aspect, degree of rockiness and mean annual temperature all had a significant effect on $W$. cedarbergensis mortality $(\mathrm{p}<0.10)$ (Table 1 : Model 3$)$. Trees in 'open' habitats did not have an increased probability of mortality (Table 1), although a significant difference in the abundance of $W$. cedarbergensis trees in rocky $(n=471)$, compared to well protected $(\mathrm{n}=277)$ and open $(\mathrm{n}=73)$ sites was observed ( $\left.\mathrm{df}=2, \mathrm{X}^{2}=289.47, \mathrm{p}<0.001\right)$. In most cases the model captured the expected direction of relationships between the response and explanatory variables. For example, the probability of mortality increased with an increase in fire frequency $(\mathrm{p}<0.05)$, while an increase in mean annual temperature was almost significant at $\alpha=0.05(\mathrm{p}=0.07)$ (Fig. 6). The predicted probability of mortality was greatest on northern, southern and western facing aspects, followed by eastern aspects (Fig. 6). Both elevation (positive) and annual precipitation (negative) had strong co-correlation with mean annual temperature $\left(R^{2}=0.59, p<0.001\right.$ and $\mathrm{R}^{2}=0.42, \mathrm{p}<0.001$, respectively). 


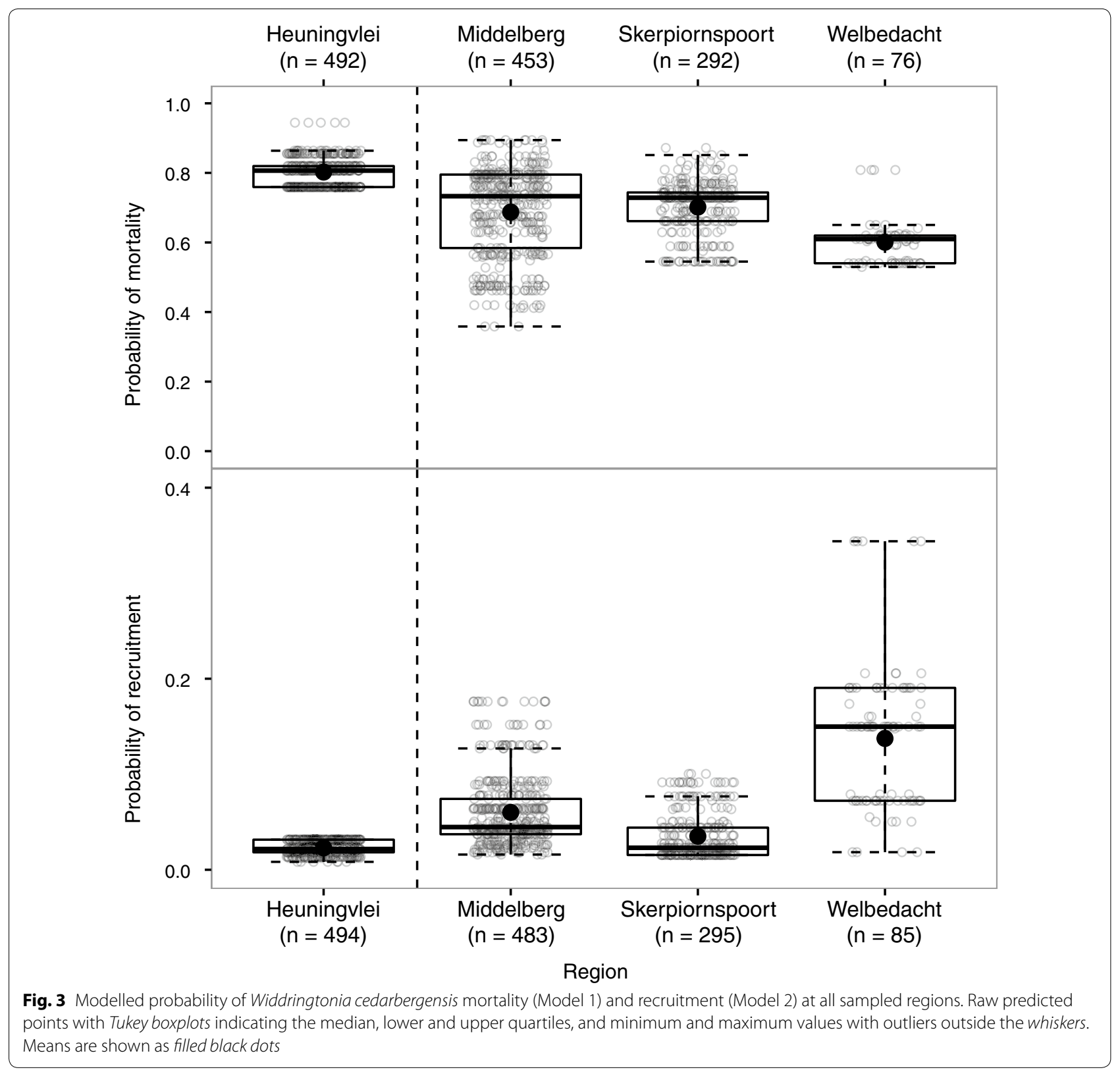

\section{Discussion}

The Cederberg was declared a Wilderness Area in 1973 giving it the highest conservation status in South Africa [31]. Grounded in the perception that W. cedarbergensis is in decline [6,7], one of the objectives for the reserve has been the conservation of this iconic tree. Palaeoecological evidence does indeed suggest that W. cedarbergensis trees were once more numerous, with a steady decline in fossil pollen deposits since the last glacial maximum [10]. The suggestion is that the decline may be attributed to long-term warming and drying of the West Coast climate in the late Quaternary that may have contributed to elevated fire frequencies [10]. It has also been proposed that prior to heavy 18th and 19th century logging $[5,6]$ the species may have occurred in denser communities. Harvesting and more frequent anthropogenic fires led to thinning and reductions in stand size, thereby establishing a positive feedback which promoted further penetration by fires, killing both seedlings and large seed-bearing adults [9].

Without access to accurate demographic records it is very difficult to reconstruct population dynamics before the 20th Century. Our more recent results suggest, however, that population densities were much higher in the 


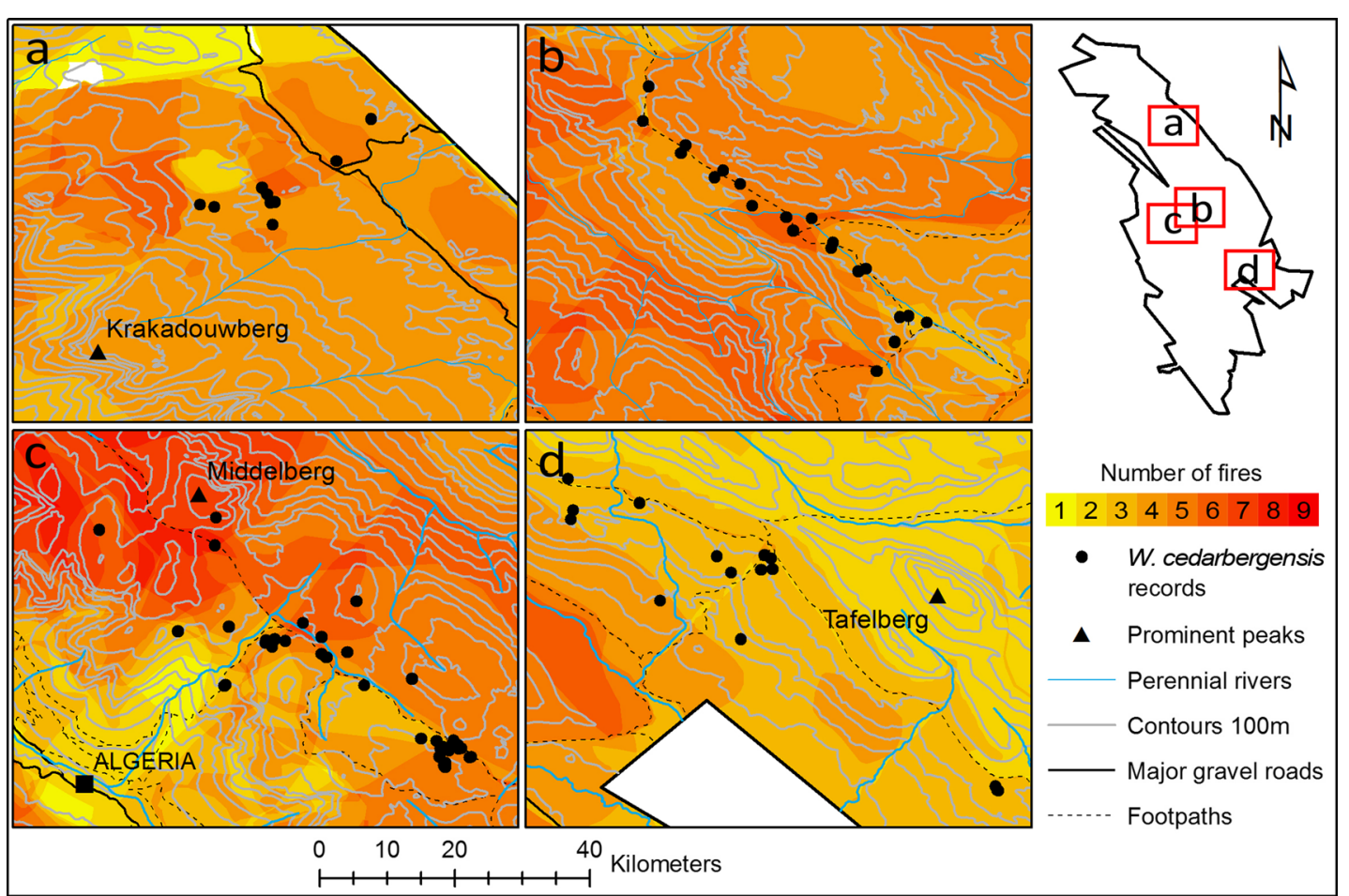

Fig. 4 Fire frequency map for the four studied regions within the Cederberg Wildnerness Area. a Heuningvlei, b Skerpioenspoort, c Middelberg and d Welbedacht. The fire record is from 1944 to 2012

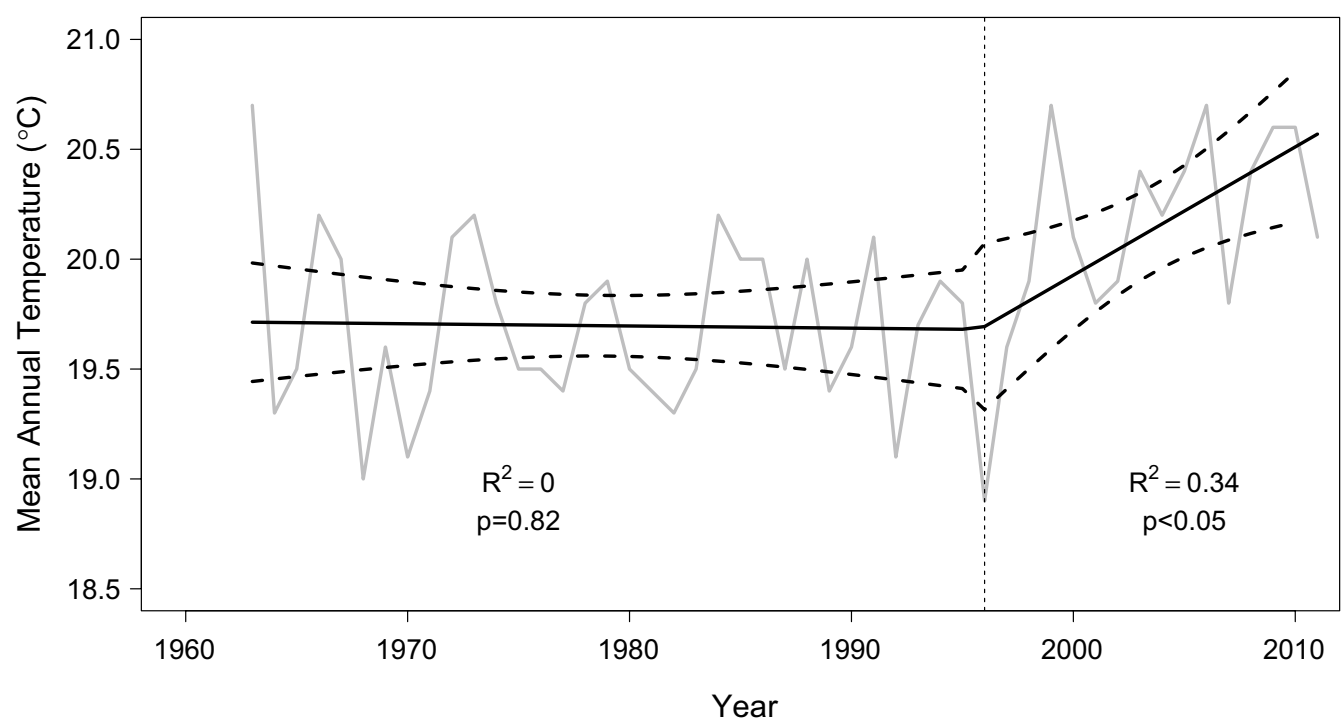

Fig. 5 Mean annual temperature $\left({ }^{\circ} \mathrm{C}\right)$ in Clanwilliam from 1963 to 2010. The solid line represents a piecewise regression with an estimated breakpoint in 1996. The dashed lines represent $95 \%$ confidence intervals. $R^{2}$ values and significance levels are attached

early part of last century than they are today and that the $W$. cedarbergensis decline has continued regardless of any management interventions $[13,32]$. In addition, our results show that the greatest declines in trees took place between the periods 1960-1987 and 2007-2013, indicating that $W$. cedarbergensis mortality has increased in the late 20th and early 21st century. Current recruitment rates are also not keeping pace with mortality at any of 
Table 1 Fitted coefficients, the standard errors, $P$ values of the generalized linear mixed-model for probability of $W$. cedarbergensis mortality across all regions (model 1 ) and in natural stands (model 3), probability of recruitment across all regions (model 2) and the Wald test of fixed effects

\begin{tabular}{|c|c|c|c|c|c|c|}
\hline \multirow[t]{2}{*}{ Predictors } & \multicolumn{2}{|l|}{ Model 1} & \multicolumn{2}{|l|}{ Model 2} & \multicolumn{2}{|l|}{ Model 3} \\
\hline & Estimate & S.E. & Estimate & S.E. & Estimate & S.E. \\
\hline \multicolumn{7}{|l|}{ (a) } \\
\hline Intercept & $-9.14^{*}$ & 2.85 & 9.23 & 5.72 & $-9.96^{*}$ & 4.40 \\
\hline Habitat-open & 0.39 & 0.45 & 1.19 & 0.76 & 0.41 & 0.61 \\
\hline Habitat-rocky & 0.26 & 0.23 & 0.38 & 0.50 & $0.55^{*}$ & 0.27 \\
\hline Aspect-north & $1.45^{* * *}$ & 0.41 & 0.00 & 0.82 & $1.99^{* * *}$ & 0.45 \\
\hline Aspect-south & 0.49 & 0.30 & 0.15 & 0.69 & $1.24^{* * *}$ & 0.34 \\
\hline Aspect-west & $0.89^{* *}$ & 0.33 & 0.78 & 0.63 & $1.43^{* * *}$ & 0.41 \\
\hline Fire frequency & 0.09 & 0.12 & -0.18 & 0.23 & $0.30^{*}$ & 0.14 \\
\hline MAT & $0.70^{* *}$ & 0.23 & $-0.96^{*}$ & 0.47 & 0.64 & 0.36 \\
\hline Random effects (R.E.) & 0.00 & 0.97 & 0.00 & 0.98 & 1.02 & 0.90 \\
\hline Predictors & $\mathrm{X}^{2}$ & $p$ value & $\mathrm{X}^{2}$ & $p$ value & $\mathrm{X}^{2}$ & $p$ value \\
\hline \multicolumn{7}{|l|}{ (b) } \\
\hline Habitat & 18.6 & 0.000 & 2.5 & 0.290 & 9.0 & 0.029 \\
\hline Aspect & 18.8 & 0.000 & 8.7 & 0.068 & 26.9 & 0.000 \\
\hline Fire frequency & 0.5 & 0.468 & 0.6 & 0.440 & 4.6 & 0.033 \\
\hline MAT & 9.6 & 0.002 & 4.2 & 0.041 & 3.2 & 0.073 \\
\hline
\end{tabular}

R.E.: $n_{\text {region }}=4 ; n_{\text {site }}=86$, R.E.: $n_{\text {region }}=4 ; n_{\text {site }}=86$, R.E.: $n_{\text {region }}=3, n_{\text {site }}=80, n_{\text {tree }}=1313, n_{\text {tree }}=1357, n_{\text {tree }}=821$

Habitat well protected and aspect-east set as intercept, MAT Mean annual temperature

$p$ values: $1<0.10,{ }^{*}<0.05,{ }^{* *}<0.01,{ }^{* * *}<0.001$

our study sites. Importantly, the spatial consistency of high mortality and low recruitment across geographically isolated populations suggests that the factors driving the decline act over the entire range of the species.

Our model identified increased fire frequency and possibly higher temperatures as the primary drivers for $W$. cedarbergensis mortality. There are more trees still alive at higher elevations with concomitant lower temperatures and greater rainfall. It has been demonstrated that a small increase in temperature can increase vapour pressure deficit (VPD) which increases tree water use resulting in an increase in mortality during severe drought due to xylem cavitation [33]. This increased mortality with increased temperature is also demonstrated by our model showing a significant increase in mortality on warmer north facing slopes.

Although our modelled results suggest W. cedarbergensis mortality is not associated with more open habitats, we found that $W$. cedarbergensis trees were positively associated with 'rockier' sites. This suggests a variable not considered in the analysis but weakly correlated to the degree of rockiness such as, for example, available ground water, may be important in W. cedarbergensis survival. Previous research has demonstrated that in rocky sites the trees source water from deep pockets between the rocks [11]. This implies a possible affinity for available water. In addition, directed secondary dispersal [34] and shadier, cooler microhabitats found in rockier environments which are beneficial in seedling establishment [3] are also likely factors that have influenced recruitment and the presence of the trees in such sites.

Temperature-induced mortality has been recognised as a global issue for many tree species $[1,2,35,36]$. The association of $W$. cedarbergensis trees with sites of lower temperatures at higher elevations and historical trends of increasing temperatures in the Cederberg, should be recognised as possible contributors to mortality. Not even a significant increase in rainfall over the course of the 20th century at the more proximal climate station at Algeria appears to have halted or reversed the negative demographic trend. Climate models for the study area [18] and globally [37] show that temperatures will continue to increase through this century, suggesting that in future favourable habitat for the trees is only likely at higher elevations [38]. Current populations of W. cedarbergensis are already at or near the highest locally attainable elevations. In addition, isolated peaks and ridges on which the trees typically occur are often separated from the nearest adjacent higher ground by lower-lying valleys dominated by fire-prone vegetation.

Given the slow rate of W. cedarbergensis growth to reproductive maturity, the median fire frequencies at 


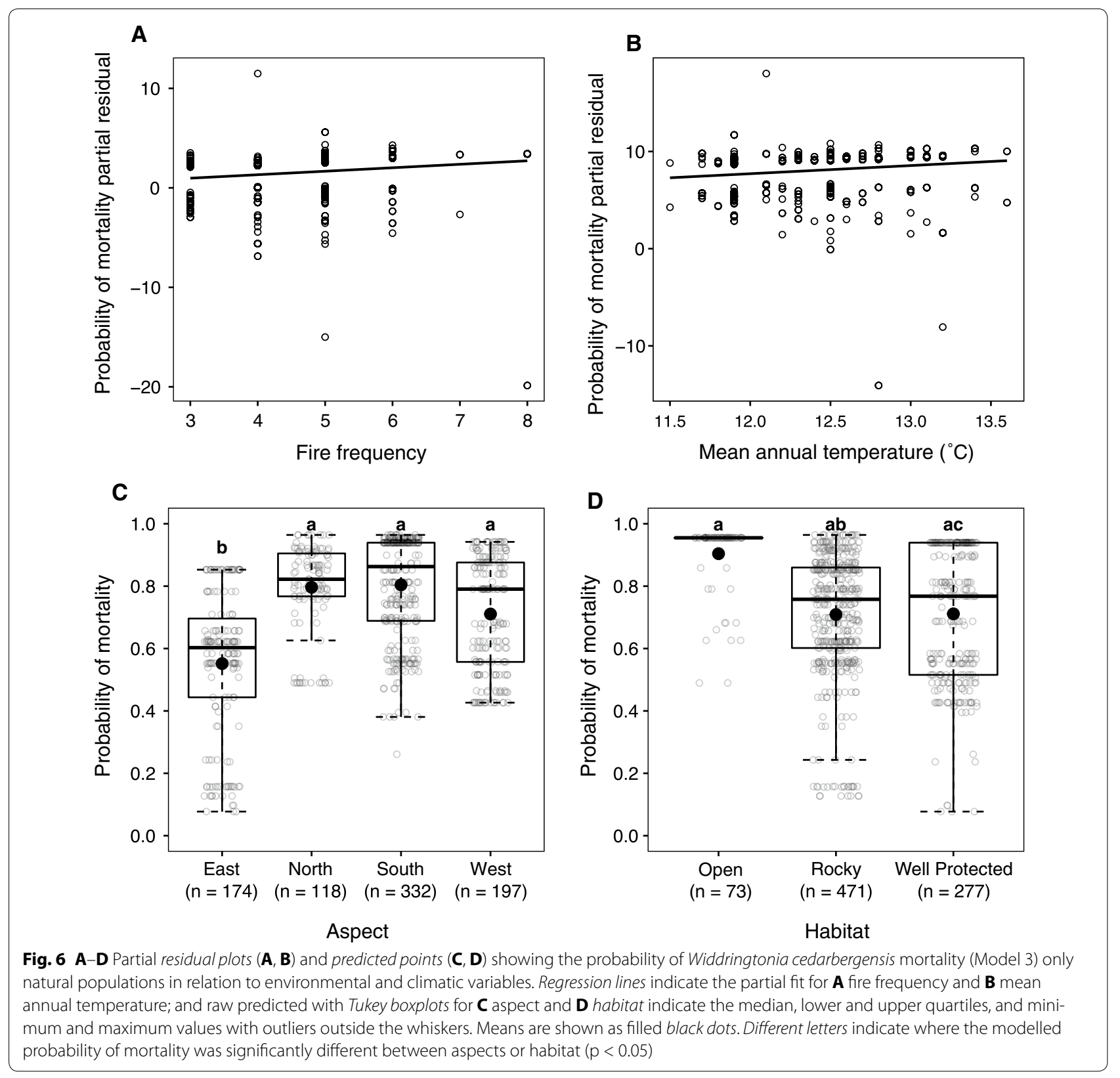

the sampled sites over the 68 year record for the Cederberg suggests that fire return intervals will likely be too short in most regions for the trees to naturally replace themselves [3]. Indeed, in some regions fire return intervals are decreasing despite a management policy of a 15-20 year return interval. Our study did not, however, determine the relative impact of less frequent, large, high intensity fires (e.g. in 1959, 1985 and more recently in January 2013), on W. cedarbergensis demography and this remains an avenue for further research . Furthermore, future studies may benefit from the use of climatic and environmental variables with a more detailed temporal and spatial resolution, particularly in view of the myriad micro-habitats and refugia that are available in terrain such as exists in the CWA.

Despite the Cederberg being declared a Wilderness Area in 1973 and one of the management foci being the conservation of the threatened $W$. cedarbergensis, our results show that there has been a significant decline in the number of trees since that time. We suggest that this continued decline is probably due to both natural and anthropogenically mediated increases in fire frequency and temperature. If modelled climate change predictions for increased warming and drying of the Cederberg Mountains [18] are realised, the future survival of the $W$. cedarbergensis is at serious risk. 


\section{Conclusions}

The outlook for W. cedarbergensis remains a concern under the current climate and fire regime. Mortality rates are too high and recruitment rates too low to sustain viable populations in the long-term. The main drivers of mortality appear to be higher temperatures and shorter fire return intervals, while high elevation, rocky, eastfacing environments represent refugia that provide fire protection, more reliable groundwater [11] and cooler microhabitats conducive to seedling establishment. Projected drying and temperature increases in the 21st century [18] suggest that the species will be under increasing pressure, both from the impacts on water balance and hydraulic failure under greater water stress, and from elevated fire frequencies.

However, there are interventions that could help sustain current populations or the establishment of new ones. Already established annual seedling out-planting programmes could be improved to increase W. cedarbergensis seedling survival. This could be done by incorporating beneficial criteria for $W$. cedarbergensis survival, as outlined in this study, when selecting sites for outplanting [32]. Of the populations which remain, a subset could be selected (based on current demographic profiles, elevation and temperature, degree of rockiness, etc.) for special protection from fire. Lastly, assisted migration [39] to more southern high-lying protected areas should be a serious consideration given the time it would take for viable populations to establish in such areas.

\section{Additional files}

Additional file 1: Table S1. Details of photographers for all 87 repeat photograph photo-pairs taken in the Cederberg Wilderness Area between 1931 and 2013.

Additional file 2: Table S2. Source, spatial and temporal resolution, and unit of measurement of environmental variables.

Additional file 3: Figure S1. Moran's / plots testing for spatial autocorrelation in model residuals. Spatial autocorrelation in generalized linear mixed-effects model residuals a) without a spatial autocovariate term and b) with a spatial autocovariate term. Significant spatial autocorrelation ( $p$ $<0.05$ ) at each distance lag is shown by black dots.

Additional file 4: Figure S2. Histograms of fire histories for each region. a) Heuningvlei, b) Skerpioenspoort, c) Middelberg and d) Welbedacht. The fire record is from 1944 to 2012.

Additional file 5: Figure S3. Annual precipitation (mm) in Algeria (1908 to 2008) and Clanwilliam (1870 to 2010). The solid lines represent regression lines. The dashed lines represent $95 \%$ confidence intervals. R2 values and significance levels are attached.

\section{Abbreviations}

CWA: cederberg wilderness area; GLMM: generalized linear mixed-effects model; SD: standard deviation; RE: random effects; MAT: mean annual temperature.

\section{Authors' contributions}

MTH conceived of the study. SLJ, JP, DB, JDMW and MTH carried out repeat photography data collection. JDMW and VV performed the statistical analysis. JDMW and SLJ drafted the manuscript. ECF critically revised the manuscript. All authors read and approved the final manuscript.

\section{Author details}

${ }_{1}^{1}$ Plant Conservation Unit, University of Cape Town, Cape Town, South Africa. ${ }^{2}$ Department of Biological Sciences, University of Cape Town, Cape Town, South Africa. ${ }^{3}$ Statistics in Ecology, Environment and Conservation, Department of Statistical Sciences, University of Cape Town, Cape Town, South Africa.

${ }^{4}$ African Climate and Development Initiative, University of Cape Town, Cape Town, South Africa.

\section{Acknowledgements}

We would like to thank Cape Nature for allowing us to work in the CWA and for providing access to the fire records. In particular we would like to acknowledge the contribution that the late Patrick Lane made to the conservation of the Clanwilliam cedar and all the flora and fauna of the CWA. The South African Weather Service and Agricultural Research Council provided climate data for the area.

\section{Competing interests}

The authors declare that they have no competing interests.

\section{Availability of data and materials}

The dataset supporting the results of this article is available in the PANGAEA ${ }^{\circledR}$ Data Publisher repository: https://doi.pangaea.de/10.1594/ PANGAEA.866937.

Received: 20 February 2016 Accepted: 4 November 2016 Published online: 30 November 2016

\section{References}

1. Allen C, Macalady A, Chenchouni H, Bachelet D, McDowell N, Vennetier M, Kitzberger T, Rigling A, Breshears D, Hogg E, Gonzalez P, Fensham R, Zhang Z, Castro J, Demidova N, Lim J-H, Allard G, Running S, Semerci A, Cobb N. A global overview of drought and heat-induced tree mortality reveals emerging climate change risks for forests. For Ecol Manag. 2010;259(4):660-84.

2. McDowell N, Allen CD. Darcy's law predicts widespread forest mortality under climate warming. Nat Clim Change. 2015;5:669-72.

3. Manders PT. An assessment of the current status of the Clanwilliam cedar (Widdringtonia cedarbergensis) and the reasons for its decline. S Afr For J. 1986;139:48-53.

4. Farjon A, February E, Higgins S, Fox S, Raimondo D. Widdringtonia cedarbergensis The IUCN Red List of Threatened Species 2013. http://dx.doi. org/10.2305/IUCN.UK.2013-1.RLTS.T30365A2793077.en. Accessed 15 Oct 2013

5. Smith CA. Early 19th century records of the Clanwilliam cedar (Widdringtonia juniperoides Endl). J S Afr For Assoc. 1955;25(1):58-65.

6. Hubbard CS. Observations on the distribution and growth rate of the Clanwilliam cedar Widdringtonia juniperoides. S Afr J Sci. 1937;33:572-86.

7. Lückhoff HA. The clanwilliam cedar: its past history and present status. J Mt Club S Afr. 1971;74:33-9.

8. Andrag RH. Studies in die Sederberge (i) Die status van die Clanwilliam sedar (Widdringtonia cedarbergensis Marsh) (ii) Buitelugontspanning Unpublished MSc thesis. Stellenbosch: University of Stellenbosch; 1977.

9. Manders PT. A transition matrix model of the population dynamics of the Clanwilliam cedar (Widdringtomia cedarbergensis) in natural stands subject to fire. For Ecol Manag. 1987;20:171-86.

10. Meadows M, Sugden J. The History of the Clanwilliam Cedar (Widdringtonia cedarbergensis): evidence from Pollen Analysis. S Afr For J. 1991;156:64-71.

11. February E, West A, Newton R. The relationship between rainfall, water source and growth for an endangered tree. Austral Ecol. 2007;32:397-402. 
12. Wingfield MJ, von Broembsen SL, Manders PT. A preliminary assessment of the threat of diseases and pests to Widdringtonia cedarbergensis. S Afr For J. 1988;147:32-5.

13. Brown PJ, Manders PT, Bands DP, Kruger FJ, Andrag RH. Prescribed burning as a conservation management practice: a case history from the Cederberg mountains, Cape Province, South Africa. Biol Conserv. 1991;56:133-50.

14. Le Maitre DC, Midgley JJ. Plant reproductive ecology. In: Cowling RM, editor. The ecology of fynbos. Cape Town: Oxford University Press; 1992. p. 135-74.

15. Manders PT. The Autecology of Widdringtonia cedarbergensis in relation to its conservation management. MSc thesis. Cape Town: University of Cape Town; 1985.

16. Fox SJ. An assessment of the population status and demographic models of Widdringtonia cedarbergensis. Unpublished Honours thesis, Department of Botany. Cape Town: University of Cape Town; 2013.

17. Higgins S, February E, Skowno A. Distribution and viability of Clanwilliam cedar (Widdringtonia cedarbergensis, Cupressaceae). Final report to WWFSA table mountain fund. 2001

18. Midgley GF, Hannah L, Millar D, Rutherford MC, Powrie LW. Assessing the vulnerability of species richness to anthropogenic climate change in a biodiversity hotspot. Glob Ecol Biogeogr. 2002;11:445-51.

19. Coates Palgrave K. Trees of Southern Africa. Cape Town: C. Struik; 1977. p. 59-60

20. Taylor HC. Cederberg: vegetation and flora. Strelitzia 3, Pretoria: National Botanical Institute; 1996.

21. Mucina $L$, Rutherford MC. The vegetation of South Africa, Lesotho and Swaziland. Strelitzia, 19. Pretoria: South African National Biodivesrity Institute; 2006.

22. Konietschke F, Placzek M, Schaarschmidt F, Hothorn LA. Nparcomp: an R software package for nonparametric multiple comparisons and simultaneous confidence intervals. J Stat Softw. 2015;64(9):1-17.

23. R Core Team. R: A language and environment for statistical computing. Vienna: R foundation for statistical computing. http://www.R-project.org/. 2014.

24. ESRI. ArcGIS desktop: release 10. Redlands: Environ Sys Res Inst; 2011.

25. Hijmans RJ, Cameron SE, Parra JL, Jones PG, Jarvis A. Very high resolution interpolated global terrestrial climate surfaces. Int J Climatol. 2005;25:1965-78.
26. Google Earth Version 7.1.2.2041. http://www.google.com/earth/index. html. Accessed 30 Nov 2015.

27. Muggeo VMR. Estimating regression models with unknown break-points. Stat Med. 2003;22:3055-71.

28. Venables WN, Ripley BD. Modern applied statistics with S. 4th ed. New York: Springer; 2002.

29. Bjornstad ON. ncf: Spatial Nonparametric Covariance Functions. R package version 1.1-7. 2016. http://CRAN.R-project.org/package=ncf. Accessed 14 June 2016.

30. Lesnoff M, Lancelot R. aod: Analysis of Overdispersed Data. R package version 1.3. 2012. http://cran.r-project.org/package=aod. Accessed 14 June 2016.

31. Smith F. Governmental relations in the management of the Cederberg Wilderness Area: some organisational aspects. Politeia. 2002;21(3):58.

32. Mustart PJ, Makua C, Juritz J, Van der Merwe SW, Wessels N. Restoration of the Clanwilliam cedar, Widdringtonia cedarbergensis: the importance of monitoring seedlings planted in the Cederberg, South Africa. Biol Conserv. 1995:72:73-6.

33. Will RE, Wilson SM, Zou CB, Hennessey TC. Increased vapor pressure deficit due to higher temperatures leads to greater transpiration and faster mortality during drought for tree seedlings common to the forestgrassland ecotone. N Phytol. 2013:200:366-74.

34. Midgley JJ, Anderson B, Bok A, Fleming T. Scatter-hoarding of Cape Proteaceae nuts by rodents. Evolut Ecol Res. 2002;4:623-6.

35. Suarez ML, Ghermandi L, Kitzberger T. Factors predisposing episodic drought-induced tree mortality in Nothofagus - site, climatic sensitivity and growth trends. J Ecol. 2004;92:954-66.

36. Williams AP, Allen CD, Macalady AK, Griffin D, Woodhouse CA, Meko DM, Swetnam TW, Rauscher SA, Seager R, Grissino-Mayer HD, Dean JS, Cook ER, Gangodagamage C, Cai M, McDowell NG. Temperature as a potent driver of regional forest drought stress and tree mortality. Nat Clim Change. 2013;3:292-7.

37. IPCC. Climate change 2013. In: Stocker TF, et al., editors. The physical science basis. Cambridge: Cambridge University Press; 2013.

38. Parmesan C. Ecological and evolutionary responses to recent climate change. Ann Rev Ecol Evol Syst. 2006;37:637-69.

39. McLachlan JS, Hellmann JJ, Schwartz MW. A framework for debate of assisted migration in an era of climate change. Conserv Policy. 2007;21(2):297-302.

\section{Submit your next manuscript to BioMed Central and we will help you at every step:}

- We accept pre-submission inquiries

- Our selector tool helps you to find the most relevant journal

- We provide round the clock customer support

- Convenient online submission

- Thorough peer review

- Inclusion in PubMed and all major indexing services

- Maximum visibility for your research

Submit your manuscript at www.biomedcentral.com/submit
() Biomed Central 